\title{
Just Get Out the Door! Importance of Walking Outside the Home for Maintaining Mobility: Findings from the Women's Health and Aging Study
}

\author{
Eleanor M. Simonsick, PhD, ${ }^{* \dagger}$ Jack M. Guralnik, MD, PhD,${ }^{\ddagger}$ Stefano Volpato, MD, MPH, ${ }^{\ddagger \mathcal{S}}$ \\ Jennifer Balfour, $P h D,{ }^{\ddagger}$ and Linda P. Fried, $M D, M P H^{\mathcal{S}}$
}

OBJECTIVES: To determine the association between volitional walking behavior and change in walking ability and lower extremity function over 1 year in functionally limited older women.

DESIGN: Longitudinal cohort study.

SETTING: Data were collected in participant's homes in Baltimore, Maryland.

PARTICIPANTS: One thousand two cognitively intact community-resident female Medicare beneficiaries aged 65 and older enrolled in the Women's Health and Aging Study.

MEASUREMENTS: Reported walking behavior and change in reported walking difficulty, usual and rapid gait speed, and lower extremity physical performance score over 1 year.

RESULTS: Of 800 functionally limited women who could walk unassisted at baseline and were alive and contacted 1 year later, $226(28 \%)$ walked regularly, at least eight blocks per week. These women exhibited better health and functioning than nonwalkers (e.g., lower prevalence of depressive and fatigue symptoms and cardiovascular disease and higher mean ankle-arm index, forced expiratory volume in the first second, and gait speed). One year later, independent of initial functional status, social-psychological and behavioral factors, and health conditions, walkers were 1.8 times $(95 \%$ confidence interval $=1.2-2.7 ; P=.002)$ more likely to maintain reported walking ability and showed less decline in customary walking speed $(0.009 \mathrm{~m} / \mathrm{s}$ vs -0.070 $\mathrm{m} / \mathrm{s} ; P=.001)$ and functional performance score $(-0.17 \mathrm{vs}$

From the *Clinical Research Branch, National Institute on Aging, Baltimore, Maryland; 'Department of Medicine, Johns Hopkins University School of Medicine, Baltimore, Maryland; ${ }^{\ddagger}$ Laboratory of Epidemiology, Demography, and Biometry, National Institute on Aging, Bethesda, Maryland;

${ }^{\S}$ Department of Clinical and Experimental Medicine, Università di Ferrara, Ferrara, Italy; and "Department of Epidemiology, University of Michigan, Ann Arbor, Michigan.

The Women's Health and Aging Study was supported by Contract NO1-AG-1-2112 from the National Institute on Aging.

Address correspondence to Dr. Simonsick, National Institute on Aging/ ASTRA, Harbor Hospital, 5th Floor, 3001 South Hanover Street, Baltimore, MD 21225. E-mail: simonsickel@grc.nia.nih.gov
$-0.73 ; P=.01)$ than women who walked less than eight blocks.

CONCLUSION: The strength, consistency, and specificity of the association between walking behavior and maintenance of mobility provide strong evidence that even a small amount of regular walking can confer short-term protection from further mobility loss in functionally limited women. The observation that most women capable of walking at least eight blocks per week were not doing so indicates the need to get more women "out the door" and to encourage those who walk a little to walk a little more. J Am Geriatr Soc 53:198-203, 2005.

Key words: aged; walking; women; mobility; physical activity

lthough, it is well established that exercise activity
protects against loss of physical function in older
adults, ${ }^{1}$ the benefit of low-level habitual activity in func-
tionally limited individuals is unknown. Longitudinal ob-
servational studies provide strong evidence that regular
moderate-to-vigorous physical activity preserves mobility
and physical capacity in functionally intact elders, ${ }^{2-7}$ and
several intervention trials have demonstrated that intensive
activity programs can improve function in debilitated older
adults. ${ }^{8-14}$ Nevertheless, the findings of these types of stud-
ies are not directly applicable to functionally limited com-
munity-resident elderly. In the first instance, the amount
and intensity of the exercise activity found to be protective
exceeds the capacity of functionally limited older adults. ${ }^{15}$
In the second case, most successful interventions follow a
rehabilitation model, and the populations targeted often
have specific health conditions ${ }^{9,12}$ or reside in institutional
settings. ${ }^{11}$ Thus, such programs are not widely available or
accessible to community-resident older adults with insidious
functional difficulties. ${ }^{16}$ Problems with recruitment, reten-
tion, and adherence suggest further that structured activity
regimens may have limited appeal for older adults. ${ }^{17,18}$
It has been established that upward of $30 \%$ of func-
tionally limited older women walk regularly, at least eight 
blocks per week. ${ }^{19}$ Although low by public health standards, ${ }^{20}$ this amount of walking represents a level of activity that is manageable and acceptable to a moderate proportion of this vulnerable population. Whether low-level habitual practice of common activities, such as walking, affects the trajectory of physical decline in functionally limited older individuals is unknown. To address this, the association between volitional walking behavior in functionally limited older women and change in reported walking difficulty, measured gait speed, and lower extremity function over 12 months were examined.

\section{METHODS}

\section{Study Population}

The source population consisted of functionally limited women aged 65 and older participating in the Women's Health and Aging Study (WHAS), a prospective investigation of disability developed and supported by the National Institute on Aging and conducted by the Johns Hopkins Medical Institutions. From an age-stratified random sample of 5,316 community-resident Medicare beneficiaries in 12 contiguous ZIP code areas in Baltimore, Maryland, 4,137 $(78 \%)$ were administered a screening questionnaire to identify women in the bottom one-third of the functional spectrum. Of those screened, $1,409(34 \%)$ met eligibility criteria - reported difficulty with one or more activities in at least two of four functional domains (self-care, instrumental activities, upper extremity, and lower extremity) and were not severely cognitively impaired (scored $>17$ on the Mini-Mental State Examination $\left.{ }^{21}\right)$. Of eligible women, $1,002(71 \%)$ completed the in-home interviewer-administered questionnaire and physical assessment and nurse-administered physical examination. ${ }^{22}$ Participants were enrolled between November 1992 and February 1995; the questionnaire and physical performance measures were readministered semiannually for 3 years. The WHAS received approval from the U.S. Office of Management and Budget and the institutional review board of the Johns Hopkins University Medical Institutions; all participants provided informed consent. More detailed descriptions of the study design and screening approach are available elsewhere. ${ }^{23,24}$

\section{Measure of Walking Behavior}

Walking behavior was determined from the following question, derived from the Harvard Alumni Activity Survey, ${ }^{25}$ "Think about the walking you do outside your home. During the last week, about how many city blocks or their equivalent did you walk?" For the primary analyses, two groups - walkers and nonwalkers - were identified, with walkers consisting of those who reported walking eight or more blocks. The cutpoint of eight blocks was selected to assure that women classified as walkers averaged at least one block per day and to be consistent with previous work. ${ }^{19}$ Overall, the amount of walking was low, with $38 \%$ not walking outside in the previous week, 34\% walking from one to seven blocks, and $28 \%$ walking eight or more blocks. For walkers, the median number of blocks walked was 16; for "nonwalkers" reporting one to seven blocks walked, the median was three blocks.

\section{Covariates - Sociodemographic, Behavioral, and} Psychological Measures

Social-psychological and behavioral factors previously associated with walking eight or more blocks independent of reported walking difficulty ${ }^{19}$ or limitation or avoidance of physical activity in older women ${ }^{26}$ were included as control variables in the current study. Sociodemographic measures consisted of age, race, and whether the participant lived alone. Behavioral factors included smoking, dichotomized as current smoker or quit within the previous year versus nonsmoker. Body mass index was determined from measured height and weight. When standing height could not be obtained, it was estimated from knee height. ${ }^{27}$ Over- and underweight were defined using the 85th and 15 th percentiles of body mass index for women aged 70 to $74(31.58 \mathrm{~kg} /$ $\mathrm{m}^{2}$ and $21.44 \mathrm{~kg} / \mathrm{m}^{2}$, respectively). ${ }^{28}$ Cane use was determined from the question, "When you walk, do you use a cane?" Personal mastery was defined as strong agreement with "I can do just about anything I really set my mind to" and strong disagreement with "I often feel helpless in dealing with the problems of life." ${ }^{29}$ Fatigue was considered present when a participant reported feeling unusually tired or weak most or all of the time in the previous month or rated her energy level in the previous month as 3 or lower on a scale from 0 to 10 , where 10 represents high energy.

\section{Covariates - Health Status Measures}

Because walking behavior could reflect another dimension of functional capacity, additional indicators of health and functional status were included. A score of 10 or more on the 30-item Geriatric Depression Scale was used to indicate high depressive symptoms. ${ }^{30,31}$ The ankle-arm index (AAI) measured severity of lower extremity peripheral arterial disease. Forced expiratory volume in the first second $\left(\mathrm{FEV}_{1}\right)$, determined from spirometry, was used to measure pulmonary function. The presence of 17 chronic diseases and conditions was ascertained using standardized algorithms based on data from participant reports of physician diagnoses, medication use, the physical examination, hospital records, and a physician questionnaire. From the algorithmbased disease determinations, indicator variables were constructed for cardiovascular disease (CVD; angina pectoris, congestive heart failure, previous myocardial infarction, or peripheral arterial disease), lower extremity musculoskeletal disease (previous hip fracture or symptomatic osteoarthritis of the hip or knee), neurological disease (Parkinsonism or stroke), and pulmonary disease (asthma, chronic bronchitis, chronic obstructive pulmonary disease, or emphysema).

\section{Measures of Mobility and Lower Extremity Function}

Level of perceived walking difficulty was determined from questions on difficulty walking for one-quarter of a mile and across a small room, phrased as follows, "By yourself, that is, without help from another person or special equipment, do you have any difficulty? ..." If yes, difficulty level was ascertained. A categorical variable ranging from 0 to 6 was constructed. Women reporting no, a little, some, or a lot of difficulty walking or unable to walk for one quarter of a mile were assigned scores of 0 to 4 , respectively; those reporting a little or some difficulty walking across a room 
were assigned a score of 5; and those with a lot of difficulty or unable to walk across a room were given a score of 6 .

Objective measures included usual and rapid walking speed over $4 \mathrm{~m}$ and summary performance score. Rapid walking speed was included as a measure of reserve capacity. ${ }^{32}$ The examiner marked out a $4-\mathrm{m}$ course (or $3 \mathrm{~m}$, if $4 \mathrm{~m}$ were unavailable) and instructed participants to walk the course at their usual walking pace. Walking aids were permitted. After two trials, participants were instructed to walk the course as fast as possible. The faster of the two usual walk trials constituted usual walking speed, and rapid walking speed was determined from the single rapid walk. Women who tried but were unable to do the walks, did not attempt the walks because they or the examiner felt it unsafe, or could not walk even with support were assigned a walking speed of $0 \mathrm{~m} / \mathrm{s}$. Walking test performance is highly reproducible. ${ }^{32}$

The 0- to 12-point performance score consisted of three 0 - to 4-point scales summarizing performance on three tests of lower extremity function-usual walking speed (described above), standing balance, and repeated chair stands. ${ }^{33,34}$ The standing balance test consists of three progressively more difficult stands - side by side, semitandem, and full tandem - each to be held for 10 seconds before attempting the next. For the chair stands, participants sat with their arms folded across their chest and were instructed to stand up without using their arms and sit down as quickly as possible five times in a row. Similar to the measured walks, women who tried but were unable to complete a test, did not attempt a test because they or the examiner felt it unsafe, or could not do the test without support were assigned a score of 0 for that test.

\section{Statistical Analysis}

The odds of maintaining perceived walking ability associated with walking eight or more blocks per week was determined from logistic regression analysis. Maintenance of walking ability was defined as having the same or a lower level of reported walking difficulty 1 year later than at baseline. To examine whether associations varied by baseline functional status, stratified analyses were conducted dichotomizing walking difficulty as low (0-2) or high (3-6). To determine the association between walking eight or more blocks and objective measures of function, adjusted mean change in usual and rapid walking speed and performance score for walkers and nonwalkers were compared between baseline and the 12-month follow-up using a general linear models procedure. For both sets of analyses, progressively more complex models were run. Model 1 includes age and baseline value of the outcome measure (i.e., walking difficulty level, usual or rapid walking speed, or performance score), Model 2 added the social-psychological and behavioral variables, and Model 3, the fully adjusted model, incorporated the health status measures. To include women with missing values for $\mathrm{AAI}$ or $\mathrm{FEV}_{1}$ in the analyses, a centering approach, subtracting the sample mean from each individual's value to create a new variable with a mean of 0 and assigning those with missing values a score of 0 , was used. Indicator variables for presence or absence of a valid AAI or spirometry test were also included. This approach allows for the inclusion of the $35 \%$ of
WHAS participants who had unacceptable spirometry results and the $5 \%$ with impalpable ankle blood pressures, largely due to poor health. Analyses were conducted using SAS PC, Version 6.12 (SAS Institute, Inc., Cary, NC).

\section{RESULTS}

Of the original 1,002 women, 73 reported inability to walk across a room unassisted and were not asked about their walking behavior; an additional seven had missing information, leaving a baseline sample of 920 . One year later, 800 of these women were alive and had known functional status; 752 were self-respondents, and 48 had proxies. Of the remaining 120, 55 had died, and 65 had no interview data because they refused $(n=51)$, were too ill $(n=9)$ or cognitively impaired $(n=4)$ to participate, or could not be located $(n=1)$. Although a similar proportion of walkers and nonwalkers were lost to follow-up, nonwalkers had higher mortality than walkers $(7.3 \%$ vs $2.4 \% ; P=.006)$.

Overall, $28 \%$ of these functionally limited older women reported walking at least eight blocks outside their home in the week before their baseline interview. As shown in Figure 1 , the percentage who walked decreased with increasing walking difficulty, although not uniformly across all levels. Just less than half who reported no difficulty walking onequarter of a mile walked, whereas around $30 \%$ with a little, some, and a lot of difficulty walked and from $6 \%$ to $9 \%$ of those unable to walk one-quarter of a mile unaided and those with a little to a lot of difficulty walking across a room had done some walking outside their home.

As Table 1 shows, walkers generally exhibited better health than nonwalkers, were younger, and had a lower

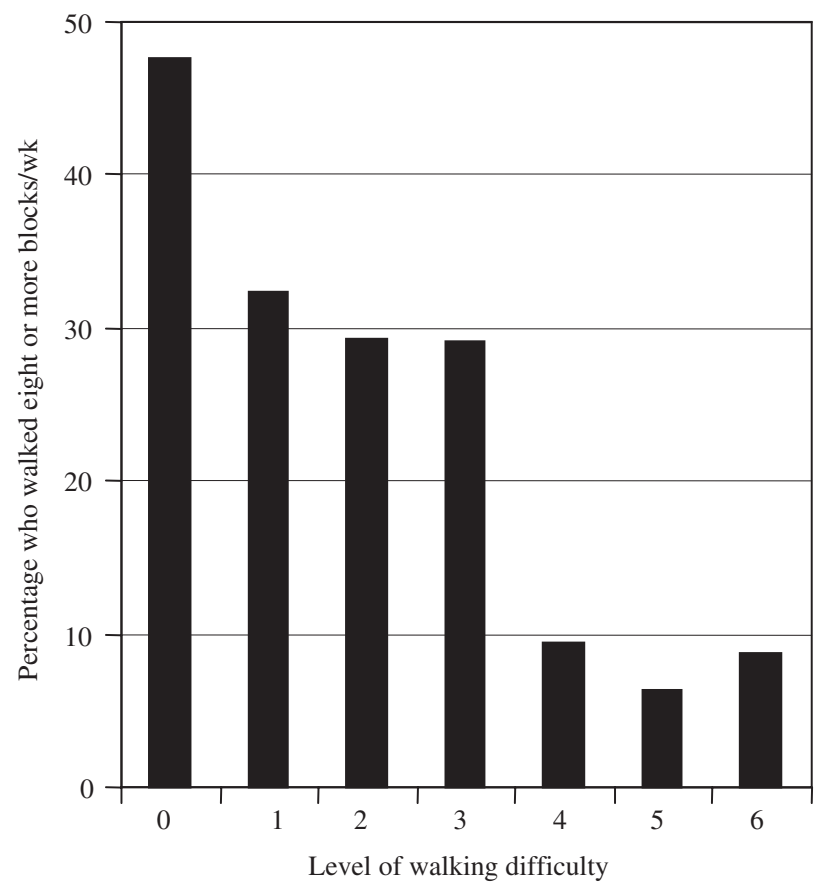

Figure 1. Percentage of subjects who walked eight or more blocks per week by reported level of walking difficulty. Levels of walking difficulty: $0=$ no, $1=$ a little, $2=$ some, $3=$ a lot of difficulty walking one-quarter of a mile; $4=$ unable to walk onequarter of a mile; and $5=$ a little to some and $6=$ a lot of difficulty walking across a small room. 
Table 1. Population Characteristics by Baseline Walking Behavior

\begin{tabular}{|c|c|c|c|}
\hline Characteristic & $\begin{array}{l}\text { Nonwalkers } \\
(n=574)\end{array}$ & $\begin{array}{l}\text { Walkers } \\
(n=226)\end{array}$ & $P$-value \\
\hline \multicolumn{4}{|l|}{$\begin{array}{l}\text { Level of reported walking } \\
\text { difficulty, \% }\end{array}$} \\
\hline 0 & 17.6 & 43.3 & \\
\hline 1 & 12.9 & 16.4 & \\
\hline 2 & 12.7 & 14.6 & \\
\hline 3 & 14.3 & 15.5 & \\
\hline 4 & 14.3 & 4.4 & \\
\hline 5 & 19.3 & 3.5 & \\
\hline 6 & 8.9 & 2.2 & .001 \\
\hline Black, \% & 32.2 & 19.9 & .001 \\
\hline Lives alone, \% & 46.9 & 54.4 & .07 \\
\hline Current smoker, \% & 15.2 & 15.0 & .97 \\
\hline $\begin{array}{l}\text { Body mass index } \\
\qquad 31.58 \mathrm{~kg} / \mathrm{m}^{2}, \%\end{array}$ & 29.6 & 23.9 & .07 \\
\hline $\begin{array}{l}\text { Body mass index } \\
\quad<21.44 \mathrm{~kg} / \mathrm{m}^{2}, \%\end{array}$ & 12.7 & 9.7 & .24 \\
\hline Strong control beliefs, \% & 21.0 & 38.0 & .001 \\
\hline Uses a cane to walk, \% & 47.2 & 23.0 & .001 \\
\hline $\begin{array}{l}\text { Low energy, tiredness or } \\
\text { weakness, } \%\end{array}$ & 27.2 & 11.1 & .001 \\
\hline $\begin{array}{l}\text { Geriatric Depression } \\
\quad \text { Scale score } \geq 10, \%\end{array}$ & 18.5 & 8.4 & .001 \\
\hline $\begin{array}{l}\text { Unascertainable } \\
\text { ankle-arm index, \% }\end{array}$ & 6.1 & 3.1 & .12 \\
\hline $\begin{array}{l}\text { Unascertainable } \mathrm{FEV}_{1} \text {, } \\
\%\end{array}$ & 35.7 & 34.1 & .66 \\
\hline \multicolumn{4}{|l|}{ Prevalent disease, \% } \\
\hline Cardiovascular & 49.5 & 38.1 & .005 \\
\hline Pulmonary & 27.7 & 27.4 & .94 \\
\hline Neurologic & 7.7 & 4.9 & .21 \\
\hline $\begin{array}{l}\text { Lower body } \\
\text { musculoskeletal }\end{array}$ & 44.8 & 44.3 & .89 \\
\hline $\begin{array}{l}\text { Usual walking speed, } \\
\text { m/sec, mean }\end{array}$ & 0.59 & 0.80 & .001 \\
\hline Age, mean & 79.0 & 75.4 & .001 \\
\hline Ankle-arm index, mean & 1.04 & 1.09 & .001 \\
\hline $\mathrm{FEV}_{1}$, mean & 1.40 & 1.55 & .001 \\
\hline
\end{tabular}

$\mathrm{FEV}_{1}=$ forced expiratory volume in the first second.

prevalence of depressive and fatigue symptoms and CVD and a higher mean AAI and $\mathrm{FEV}_{1}$. Prevalence of other conditions, including pulmonary, neurological, and lower extremity musculoskeletal disease and unascertainable AAI or
$\mathrm{FEV}_{1}$ did not differ between groups. Walkers had better functional status, as evidenced by their faster walking speed, lower prevalence of severe walking difficulty, and lower rate of cane use. Additionally, a higher percentage of walkers had strong control beliefs, and a lower percentage was black.

Table 2 provides the odds of maintaining perceived walking ability over 12 months associated with baseline walking behavior. Accounting for age and baseline walking difficulty level, walkers were twice as likely as nonwalkers to maintain their walking capacity 1 year later. Controlling for social-psychological and behavioral differences modestly reduced the advantage of walkers over nonwalkers. Including the health status indicators had no additional effect. The higher odds of walkers maintaining walking ability was present whether baseline difficulty level was low or high, although walkers with more severe difficulty derived a greater relative benefit from walking.

Figures 2 and 3 illustrate the mean change in usual and rapid walking speed and performance score for walkers and nonwalkers over 12 months; Table 3 provides added detail of the same findings. A negative value signifies decline. On every measure, walkers showed less deterioration than nonwalkers, exhibiting no decline in usual walking speed and more modest declines in rapid walking speed and overall lower extremity performance.

\section{DISCUSSION}

Older functionally limited women who walked the equivalent of at least eight blocks per week outside of their home were better able to maintain their functional capacity and walking ability than women who walked less or did not get out the door at all. The protective effect of walking was largely specific to walking ability as measured by change in self-perceived difficulty and walking speed; the association with a more global measure of lower extremity function, the summary performance score, was substantially weaker. Getting out the door and walking, even just two blocks per day on average, appears to have great importance for women with the most severe limitations. Although walking at least eight blocks per week may preserve customary walking speed over a 1-year period, findings concerning rapid walking pace indicate that more activity may be necessary to protect against loss of reserve capacity, because both walkers and nonwalkers experienced decline.

There are two potential limitations to this work. First, even though several indicators of health and functional status, including baseline level of the outcome examined, were

Table 2. Adjusted Odds of Maintaining Perceived Walking Ability 1 Year Later Associated with Walking at Least Eight Blocks per Week at Baseline

\begin{tabular}{|c|c|c|c|}
\hline \multirow{2}{*}{$\begin{array}{l}\text { Maintained Walking } \\
\text { Ability }\end{array}$} & Model 1 & Model 2 & Model 3 \\
\hline & \multicolumn{3}{|c|}{ Odds Ratio (95\% Confidence Interval) $P$-value } \\
\hline Overall & $1.99(1.39-2.83)<.001$ & $1.79(1.23-2.60) .002$ & $1.82(1.24-2.67) .001$ \\
\hline $\begin{array}{l}\text { Baseline difficulty level } \\
0-2\end{array}$ & & & $1.63(1.02-2.60) .040$ \\
\hline $3-6$ & & & $2.60(1.22-5.57) .014$ \\
\hline
\end{tabular}




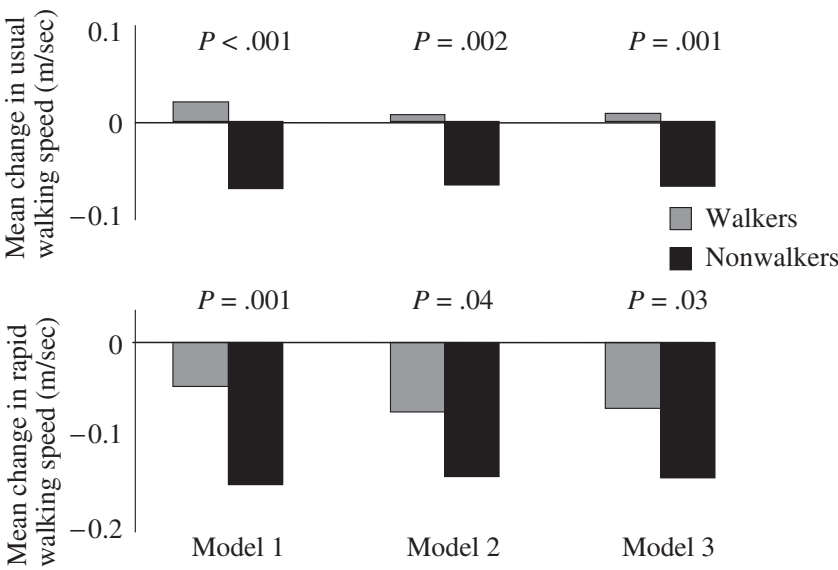

Figure 2. Adjusted mean change in usual and rapid walking speed over 1 year by baseline walking category. Model 1: Adjusted for age and baseline usual or rapid walking speed. Model 2: Adjusted for the factors in Model 1 plus race, lives alone or with others, cane use, smoking status, over- and underweight, control beliefs, and fatigue symptoms. Model 3: Adjusted for the factors in Model 2 plus the presence or absence of cardiovascular, pulmonary, neurological, and lower body musculoskeletal disease and high depressive symptoms, ankle-arm index, and forced expiratory volume in the first second.

controlled, it is still possible that the observed benefit of walking eight or more blocks per week simply reflects the better health status of the walkers than the nonwalkers. To evaluate this possibility, a distinction was made within the "nonwalkers" of women who reported walking one to seven blocks, that is, women capable of walking out of doors. In the fully adjusted model, these women showed less decline in usual walking speed than those who walked zero blocks ( $-0.034 \mathrm{~m} / \mathrm{s}$ vs $-0.108 \mathrm{~m} / \mathrm{s} ; P=.003$ ) but greater decline than women who walked at least eight blocks $(-0.034 \mathrm{~m} / \mathrm{s}$ vs $0.016 \mathrm{~m} / \mathrm{s} ; P=.06)$. Although these results do not negate the possibility that walking eight or more blocks reflects an uncontrolled dimension of functional capacity, the observation that women capable of walking out

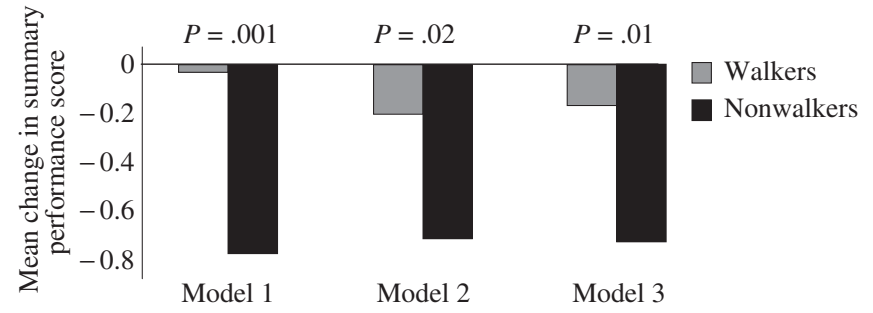

Figure 3. Adjusted mean change in summary performance score over 1 year by baseline walking category. Model 1: Adjusted for age and baseline performance score (0-12). Model 2: Adjusted for the factors in Model 1 plus race, lives alone or with others, cane use, smoking status, over- and underweight, control beliefs, and fatigue symptoms. Model 3: Adjusted for the factors in Model 2 plus the presence or absence of cardiovascular, pulmonary, neurological, and lower body musculoskeletal disease and high depressive symptoms, ankle-arm index, and forced expiratory volume in the first second.

of doors who walked less frequently did not fare as well as women who walked at least eight blocks supports the presence of a real benefit of walking.

The second limitation concerns the measure of walking behavior. Even though the question comes from a reliable and validated instrument, ${ }^{25}$ blocks walked in the previous week may not reliably represent habitual walking behavior. Although activity level is generally stable from year to year, ${ }^{35}$ it may vary greatly throughout the year because of changes in weather and acute and chronic changes in health and functioning. To examine the consistency of response over time, walking behavior was examined at the 6-month follow-up. Of women classified as nonwalkers at baseline, $15 \%(\mathrm{n}=85)$ reported walking at least eight blocks at the 6-month assessment; of those classified as walkers, 38\% $(\mathrm{n}=85)$ reported walking less than eight blocks 6 months later. When the women who were nonwalkers at baseline but were walkers at the 6-month follow-up were recategorized as walkers, using the fully adjusted model, mean change in usual walking speed becomes $0.025 \mathrm{~m} / \mathrm{s}$ versus $-0.095 \mathrm{~m} / \mathrm{s} \quad(P<.001)$ for walkers and nonwalkers,

Table 3. Adjusted Mean Change in Lower-Extremity Functional Performance 1 Year Later by Baseline Walking Amount

\begin{tabular}{|c|c|c|c|c|c|c|}
\hline \multirow{2}{*}{ Performance } & \multicolumn{2}{|c|}{ Model 1* } & \multicolumn{2}{|c|}{ Model $2^{\dagger}$} & \multicolumn{2}{|c|}{ Model $3^{\ddagger}$} \\
\hline & \multicolumn{6}{|c|}{ Mean Change ( $P$-value) } \\
\hline \multicolumn{7}{|l|}{ Usual walking speed, $\mathrm{m} / \mathrm{sec}$} \\
\hline Walked $\geq 8$ blocks/week & 0.021 & $(<.001)$ & 0.007 & $(.002)$ & 0.009 & $(.001)$ \\
\hline Walked $0-7$ blocks/week & -0.073 & & -0.069 & & -0.070 & \\
\hline \multicolumn{7}{|l|}{ Rapid walking speed, $\mathrm{m} / \mathrm{sec}$} \\
\hline Walked $\geq 8$ blocks/week & -0.048 & $(.001)$ & -0.075 & $(.04)$ & -0.072 & $(.03)$ \\
\hline \multicolumn{7}{|l|}{ Performance score, points } \\
\hline $\begin{array}{l}\text { Walked } \geq 8 \text { blocks/week } \\
\text { Walked } 0-7 \text { blocks/week }\end{array}$ & $\begin{array}{l}-0.032 \\
-0.775\end{array}$ & $(.001)$ & $\begin{array}{l}-0.204 \\
-0.712\end{array}$ & $(.02)$ & $\begin{array}{l}-0.169 \\
-0.726\end{array}$ & $(.01)$ \\
\hline
\end{tabular}

Model $3^{\ddagger}$

\footnotetext{
* Mean change adjusted for age and baseline usual or rapid walking speed or performance score (0-12).

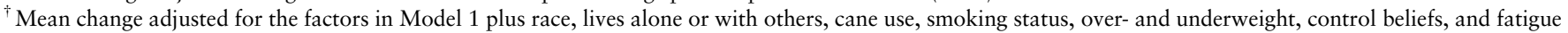
symptoms.

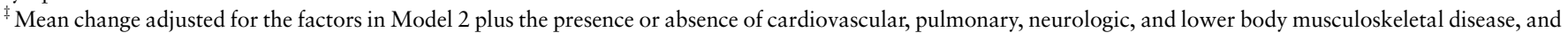
high depressive symptoms, ankle-arm index, and forced expiratory volume in the first second.
} 
respectively. Thus it appears that reliance on baseline reports only, as was done in the main analyses, provides a conservative estimate of the protective effect of walking; the actual effect may be much greater.

This study extends the findings from observational studies on the benefits of physical activity, volitional walking in particular, to functionally limited community-resident older women. Results are consistent with recent observations that walking and engagement in moderately vigorous activities confer modest health benefits. ${ }^{14,36-38}$ Although walking eight blocks per week represents an extremely low level of physical activity, the study cohort represents the bottom one-third of the functional spectrum in the community, a group excluded from most studies of physical activity. ${ }^{10,14,16}$ Nevertheless, the greatest benefit was found in the large subset with the most severe limitations.

The strength, persistence, consistency, and specificity of the relationship between walking eight or more blocks per week outside the home and maintenance of walking ability provide compelling evidence that even a small amount of regular walking offers short-term protection from further mobility loss, but for longer-term protection and to retain reserve capacity, it may be necessary to walk more frequently or for longer distances. Nevertheless, the observation that more than half the women capable of walking out of doors walked less than eight blocks per week and that more than one-quarter of the women who did not walk outside at all reported no or only some walking difficulty, indicates a sizable population who could benefit from even a small increase in activity. To delay loss of mobility, more women need to get "out the door," and those who walk a little need to be encouraged to walk a little more.

\section{REFERENCES}

1. Ettinger WH. Physical activity and older people: A walk a day keeps the doctor away. J Am Geriatr Soc 1996;44:207-208.

2. Stuck AE, Walthert JM, Nikolas T et al. Risk factors for functional status decline in community-living elderly people: A systematic literature review. Soc Sci Med 1999;48:445-469.

3. Wagner EH, LaCroix AZ, Buchner DM et al. Effects of physical activity on health status in older adults. I. Observational studies. Annu Rev Public Health 1992;13:451-468.

4. LaCroix AZ, Guralnik JM, Berkman LF et al. Maintaining mobility in late life. II. Smoking, alcohol consumption, physical activity and body mass index. Am J Epidemiol 1993;137:858-869.

5. Clark DO. The effect of walking on lower body disability among older blacks and whites. Am J Public Health 1996;86:57-61.

6. Simonsick EM, Lafferty ME, Phillips CL et al. Risk due to inactivity in physically capable older adults. Am J Public Health 1993;83:1443-1450.

7. Mor V, Murphy J, Masterson-Allen S et al. Risk of functional decline among well elders. J Clin Epidemiol 1989;42:895-904.

8. Buchner DM, Beresford SAA, Larson EB et al. Effects of physical activity on health status in older adults. II. Intervention studies. Annu Rev Public Health 1992;13:469-488.

9. Brown M, Sinacore DR, Ehsani AA et al. Low-intensity exercise as a modifier of physical frailty in older adults. Arch Phys Med Rehabil 2000;81:960-965.

10. King AC, Pruitt LA, Phillips W et al. Comparative effects of two physical activity programs on measured and perceived physical functioning and other health-related quality of life outcomes in older adults. J Gerontol A Biol Sci Med Sci 2000;55A:M74-M83.

11. Fiatarone MA, O'Neill EF, Ryan ND et al. Exercise training and nutritional supplementation for physical frailty in very elderly people. N Engl J Med 1994;330:1769-1775.

12. Ettinger WH, Burns R, Messier SP. A randomized trial comparing aerobic exercise and resistance exercise with a health education program in older adults with knee osteoarthritis. The Fitness Arthritis and Seniors Trial (FAST) JAMA 1997;277:25-31.

13. Skelton DA, Young A, Greig CA et al. Effects of resistance training on strength, power, and selected functional abilities of women aged 75 and older. J Am Geriatr Soc 1995;43:1081-1087.

14. Cress ME, Buchner DM, Questad KA et al. Exercise: Effects on physical functional performance in independent older adults. J Gerontol A Biol Sci Med Sci 1999;54A:M242-M248.

15. Dallosso HM, Morgan K, Bassey EJ et al. Levels of customary physical activity among the old and the very old living at home. J Epidemiol Community Health 1988;42:121-127.

16. King AC, Rejeski WJ, Buchner DM. Physical activity interventions targeting older adults. A critical review and recommendations. Am J Prev Med 1998; 15:316-333.

17. Blair SN, Garcia ME. Get up and move: A call to action for older men and women. J Am Geriatr Soc 1996;44:599-600.

18. Chao D, Foy CG, Farmer D. Exercise adherence among older adults. Challenges and strategies. Control Clin Trials 2000;21:212S-217S.

19. Simonsick EM, Guralnik JM, Fried LP. Who walks? Factors associated with walking behavior in disabled older women with and without self-reported walking difficulty. J Am Geriatr Soc 1999;47:672-680.

20. Pate RR, Pratt M, Blair SN et al. Physical activity and public health: A recommendation from the Centers of Disease Control and Prevention and the American College of Sports Medicine. JAMA 1995;273:402-407.

21. Folstein MF, Folstein SF, McHugh PR 'Mini-mental state'. A practical method for grading the cognitive state of patients for the clinician. J Psychiatr Res 1975;12:189-198.

22. Simonsick EM, Maffeo CE, Rogers SK et al. Methodology and feasibility of a home-based examination in disabled older women: The Women's Health and Aging Study. J Gerontol A Biol Sci Med Sci 1997;52A:M264-M274.

23. Guralnik JM, Fried LP. Screening the community-dwelling population for disability. In: Guralnik JM, Fried LP, Simonsick EM et al., eds. The Women's Health and Aging Study: Health and Social Characteristics of Older Women with Disability. Bethesda, MD: National Institute on Aging, 1995, pp 9-18.

24. Kasper JD, Shaprio S, Guralnik JM et al. Designing a community study of moderately to severely disabled older women. The Women's Health and Aging Study. Ann Epidemiol 1999;9:498-507.

25. Lee IM, Paffenbarger RS Jr, Hsieh CC. Time trends in physical activity among college alumni, 1962-88. Am J Epidemiol 1992;135:915-925.

26. Satariano WA, Haight TJ, Tager IB. Reasons given by older people for limitation or avoidance of leisure time physical activity. J Am Geriatr Soc 2000; 48:505-512.

27. Chumlea WC, Roche AF, Steinbaugh ML. Estimating stature from knee height for persons 60 to 90 years of age. J Am Geriatr Soc 1985;33:116-120.

28. Must A, Dallal GE, Dietz WH. Reference data for obesity: 85th and 95th percentiles of body mass index $\left(\mathrm{wt} / \mathrm{ht}^{2}\right)$ and triceps skinfold thickness. Am J Clin Nutr 1991;53:839-846.

29. Pearlin LI, Schooler C. The structure of coping. J Health Soc Behav 1978;18: $2-21$.

30. Yesavage JA, Brink TL, Rose TL et al. Development and validation of a geriatric depression screening scale: A preliminary report. J Psychiatr Res 1983; $17: 37-49$.

31. Lyness JM, Noel TK, Cox C et al. Screening for depression in elderly primary care patients: A comparison of the Center for Epidemiologic Studies-Depression Scale and the Geriatric Depression Scale. Arch Intern Med 1997;157:449_ 454.

32. Simonsick EM, Gardner AW, Poehlman ET. Assessment of physical function and exercise tolerance in older adults: Reproducibility and comparability of five measures. Aging Clin Exp Res 2000;12:274-280.

33. Guralnik JM, Simonsick EM, Ferrucci L et al. A short physical performance battery assessing lower extremity function: Association with self-reported disability and prediction of mortality and nursing home admission. J Gerontol Med Sci 1994;49:M85-M94.

34. Guralnik JM, Ferrucci L, Simonsick EM et al. Lower-extremity function in persons over the age of 70 years as a predictor of subsequent disability. $\mathrm{N} \mathrm{Engl}$ J Med 1995;332:556-561.

35. Armstrong GK, Morgan K. Stability and change in levels of habitual physical activity in later life. Age Ageing 1998;27:17-23.

36. LaCroix AZ, Leveille SG, Hecht JA et al. Does walking decrease the risk of cardiovascular disease hospitalizations and death in older adults? J Am Geriatr Soc 1996;44:113-120.

37. Hakim AA, Petrovitch H, Burchfiel CM et al. Effects of walking on mortality among nonsmoking retired men. N Engl J Med 1998;338:94-99.

38. Manson JE, Hu FB, Rich-Edwards JW et al. A prospective study of walking as compared with vigorous exercise in the prevention of coronary heart disease in women. N Engl J Med 1999;341:650-658. 